\title{
Coupled Fixed Point Theorems Under Nonlinear Contractive Conditions in G-Metric spaces
}

\author{
Hans Raj \\ Department of Mathematics, \\ Deenbandhu Chhotu Ram University of Science \& Technology, \\ Murthal, Sonepat, Haryana, India
}

\section{ABSTRACT}

The aim of this paper is to prove a number of coupled fixed point theorems under $\varphi$-contractions for a mapping $F: X \times X \rightarrow X$ in G-metric spaces. The given result is conversion of the result of Erdal Karapinar et al. [3] into G-metric space with coupled fixed point theorem.
\end{abstract}

\section{General Terms:}

$54 \mathrm{~A} 05$

\section{Keywords:}

G-metric space, Coupled fixed point, Mixed monotone property

\section{INTRODUCTION}

The Banach contraction principle is the most powerful tool in the history of fixed point theory. Boyd and Wong [2] extended the Banach contraction principle to the nonlinear contraction mappings. The notion of coupled fixed point was intiated by Gnana Bhaskar and Lakshmikantham [1] in 2006. After this many authors worked on coupled fixed point theorems. The notion of G-metric space is given by Mustafa and Sims [6] as a generalization of metric spaces in 2006. Based on the concept of G-metric spaces, Mustafa et al. [7, 4, 5] proved several fixed point theorems for mappings satisfying different contractive conditions.

\section{PRELIMINARIES}

Definition $2.1 \mathrm{SEE}$ [6]. Let $X$ be a nonempty set, and let $G: X \times X \times X \rightarrow R^{+}$, be a function satisfying:

(G1) $G(x, y, z)=0$ if $x=y=z$

(G2) $0<G(x, x, y)$, for all $x, y \in X$; with $x \neq y$,

(G3) $G(x, x, y) \leq G(x, y, z)$, for all $x, y, z \in X$ with $z \neq y$,

(G4) $G(x, y, z)=G(x, z, y)=G(y, z, x)=\cdots$ (symmetry in all three variables), and

(G5) $G(x, y, z) \leq G(x, a, a)+G(a, y, z)$, for all $x, y, z, a \in X$, (rectangle inequality),

\author{
Nawneet Hooda \\ Department of Mathematics, \\ Deenbandhu Chhotu Ram University of Science \& Technology,
}

then the function $G$ is called a generalized metric, or, more specifically a G-metric on $X$, and the pair $(X, G)$ is a $G$-metric space.

Definition 2.2 SeE [6]. A G-metric space $(X, G)$ is symmetric if

(G6) $G(x, y, y)=G(x, x, y)$, for all $x, y \in X$.

Definition 2.3 SeE [1]. An element $(x, y) \in X \times X$ is said to be a coupled fixed point of the mapping $F: X \times X \rightarrow X$ if

$$
F(x, y)=x \quad \text { and } \quad F(y, x)=y .
$$

DEFINITION 2.4 SEE [1]. Let $(X, \leq)$ be a partially ordered set and $F: X \times X \rightarrow X$ be a mapping.

$F$ is said to have the mixed monotone property if $F(x, y)$ is monotone non-decreasing in $x$ and is monotone non-increasing in $y$, that is, for any $x, y \in X$,

$$
x_{1} \leq x_{2} \quad \Rightarrow \quad F\left(x_{1}, y\right) \leq F\left(x_{2}, y\right), \quad \text { for } x_{1}, x_{2} \in X
$$

and

$$
y_{1} \leq y_{2} \quad \Rightarrow \quad F\left(x, y_{2}\right) \leq F\left(x, y_{1}\right), \quad \text { for } y_{1}, y_{2} \in X .
$$

By following Matkowski [7], we let $\Phi$ be the set of all nondecreasing functions $\varphi:[0,+\infty) \rightarrow[0,+\infty)$ such that $\lim _{n \rightarrow+\infty} \varphi n(t)=0$ for all $t>0$. Then, it is an easy matter to show that

(1) $\phi(t)<0$ for all $t>0$,

(2) $\phi(0)=0$.

In this paper, some coupled fixed point theorems are proved for a mapping $F: X \times X \rightarrow X$ satisfying a contractive condition based on some $\varphi \in \Phi$.

\section{MAIN RESULTS}

THEOREM 3.1. Let $(X, \leq)$ be a partially ordered set and $(X, G)$ a complete $G$-metric space. Let $F: X \times X \rightarrow X$ be a continuous mapping such that $F$ has the mixed monotone property. 
Assume that there exists $\varphi \in \Phi$ such that

$$
\begin{aligned}
& G(F(x, y), F(u, v), F(u, v)) \\
& \quad \leq \varphi[\max (G(x, u, u), G(y, v, v))]
\end{aligned}
$$

for all $x, y, u, v \in X$ with $x \geq u$ and $y \leq v$.

If there exist $x_{0}, y_{0} \in X$ such that $x_{0} \leq F\left(x_{0}, y_{0}\right)$ and $y_{0} \geq$ $F\left(y_{0}, x_{0}\right)$, then $F$ has a coupled fixed point.

Proof. Suppose $x_{0}, y_{0} \in X$ are such that $x_{0} \leq F\left(x_{0}, y_{0}\right)$ and $y_{0} \geq F\left(y_{0}, x_{0}\right)$. Define

$$
x_{1}=F\left(x_{0}, y_{0}\right) \quad \text { and } \quad y_{1}=F\left(y_{0}, x_{0}\right) .
$$

Then, $x_{0} \leq x_{1}, y_{0} \geq y_{1}$. Again, define $x_{2}=F\left(x_{1}, y_{1}\right)$ and $y_{2}=F\left(y_{1}, x_{1}\right)$. Since $F$ has the mixed monotone property, we have $x_{0} \leq x_{1} \leq x_{2}$ and $y_{2} \leq y_{1} \leq y_{0}$.

Continuing like this, we can construct two sequences $x_{n}$ and $y_{n}$ in $X$ such that

$$
\left.\begin{array}{l}
x_{n}=F\left(x_{n-1}, y_{n-1}\right) \leq x_{n+1}=F\left(x_{n}, y_{n}\right) \text { and } \\
y_{n+1}=F\left(y_{n}, x_{n}\right) \leq y_{n}=F\left(y_{n-1}, x_{n-1}\right) .
\end{array}\right\}
$$

if, for some integer $n$, we have

$$
\left(x_{n+1}, y_{n+1}\right)=\left(x_{n}, y_{n}\right),
$$

then

$$
x_{n}=F\left(x_{n}, y_{n}\right) \quad \text { and } \quad y_{n}=F\left(y_{n}, x_{n}\right)
$$

that is, $\left(x_{n}, y_{n}\right)$ is a coupled fixed point of $F$. Thus, we suppose that $\left(x_{n+1}, y_{n+1}\right) \neq\left(x_{n}, y_{n}\right)$ for all $n \in N$; that is, we assume that either $x_{n+1} \neq x_{n}$ or $y_{n+1} \neq y_{n}$. For any $n \in N$, we have

$$
\begin{aligned}
& G\left(x_{n+1}, x_{n}, x_{n}\right) \\
& =G\left(F\left(x_{n}, y_{n}\right), F\left(x_{n-1}, y_{n-1}\right), F\left(x_{n-1}, y_{n-1}\right)\right) \\
& \leq \varphi\left(\max \left(G\left(x_{n}, x_{n-1}, x_{n-1}\right), G\left(y_{n}, y_{n-1}, y_{n-1}\right)\right)\right. \\
& G\left(y_{n}, y_{n+1}, y_{n+1}\right) \\
& =G\left(F\left(y_{n-1}, x_{n-1}\right), F\left(y_{n}, x_{n}\right), F\left(y_{n}, x_{n}\right)\right) \\
& \leq \varphi\left(\max \left(G\left(y_{n-1}, y_{n}, y_{n}\right), G\left(x_{n-1}, x_{n}, x_{n}\right)\right)\right.
\end{aligned}
$$

From eq. (4) we get that

$$
\begin{aligned}
& \max \left(G\left(x_{n+1}, x_{n}, x_{n}\right), G\left(y_{n}, y_{n+1}, y_{n+1}\right)\right) \\
& \quad \leq \varphi\left(\max \left(G\left(x_{n}, x_{n-1}, x_{n-1}\right), G\left(y_{n-1}, y_{n}, y_{n}\right)\right)\right.
\end{aligned}
$$

By continuing the process of eq. (5) we get

$$
\left.\begin{array}{l}
\max \left(G\left(x_{n+1}, x_{n}, x_{n}\right), G\left(y_{n}, y_{n+1}, y_{n+1}\right)\right) \\
\leq \varphi\left(\max \left(G\left(x_{n}, x_{n-1}, x_{n-1}\right), G\left(y_{n-1}, y_{n}, y_{n}\right)\right)\right. \\
\leq \varphi^{2}\left(\max \left(G\left(x_{n-1}, x_{n-2}, x_{n-2}\right), G\left(y_{n-2}, y_{n-1}, y_{n-1}\right)\right)\right. \\
\vdots \\
\leq \varphi^{n}\left(\max \left(G\left(x_{1}, x_{0}, x_{0}\right), G\left(y_{0}, y_{1}, y_{1}\right)\right)\right.
\end{array}\right\}
$$

Now, we will show that $x_{n}$ and $y_{n}$ are Cauchy sequences in $X$. Let $\varepsilon>0$. Since

$$
\lim _{n \rightarrow \infty} \varphi^{n}\left(\max \left(G\left(x_{1}, x_{0}, x_{0}\right), G\left(y_{0}, y_{1}, y_{1}\right)\right)=0\right.
$$

and $\varepsilon>\varphi(\varepsilon)$, there exist $n_{0} \in N$ such that

$$
\begin{array}{r}
\varphi^{n}\left(\max \left(G\left(x_{1}, x_{0}, x_{0}\right), G\left(y_{0}, y_{1}, y_{1}\right)\right)<\varepsilon-\varphi(\varepsilon)\right. \\
\text { for all } n=n_{0}
\end{array}
$$

This implies that

$$
\max \left(G\left(x_{n+1}, x_{n}, x_{n}\right), G\left(y_{n}, y_{n+1}, y_{n+1}\right)\right)<\varepsilon-\varphi(\varepsilon)
$$

$$
\text { for all } n=n_{0}
$$

For $m, n \in N$, we will prove by induction on $m$ that

$$
\begin{array}{r}
\max \left(G\left(x_{n}, x_{m}, x_{m}\right), G\left(y_{n}, y_{m}, y_{m}\right)\right)<\varepsilon \\
\text { for all } m \geq n \geq n_{0}
\end{array}
$$

Since $\varepsilon-\varphi(\varepsilon)<\varepsilon$, then by using (9) we get that (10) holds when $m=n+1$. Now suppose that (10) holds for $m=k$. For $m=k+1$, we have

$$
\begin{aligned}
& G\left(x_{n}, x_{k+1}, x_{k+1}\right) \\
& \leq G\left(x_{n}, x_{n+1}, x_{n+1}\right)+G\left(x_{n+1}, x_{k+1}, x_{k+1}\right) \\
& \leq \varepsilon-\varphi(\varepsilon)+G\left(F\left(x_{n}, y_{n}\right), F\left(x_{k}, y_{k}\right), F\left(x_{k}, y_{k}\right)\right) \\
& \leq \varepsilon-\varphi(\varepsilon)+\varphi\left(\max \left(G\left(x_{n}, x_{k}, x_{k}\right), G\left(y_{n}, y_{k}, y_{k}\right)\right)\right. \\
& <\varepsilon-\varphi(\varepsilon)+\varphi(\varepsilon) .
\end{aligned}
$$

Similarly, we show that

$$
G\left(y_{n}, y_{k+1}, y_{k+1}\right)<\varepsilon .
$$

Hence, we have

$$
\max \left(G\left(x_{n}, x_{k+1}, x_{k+1}\right), G\left(y_{n}, y_{k+1}, y_{k+1}\right)\right)<\varepsilon
$$

Thus, (10) holds for all $m \geq n \geq n_{0}$. Hence, $x_{n}$ and $y_{n}$ are Cauchy sequences in $X$.

Since $X$ is a complete G-metric space, there exist $x$ and $y \in X$ such that $x_{n}$ and $y_{n}$ converge to $x$ and $y$ respectively. Finally, we show that $(x, y)$ is a coupled fixed point of $F$. Since $F$ is continuous and $\left(x_{n}, y_{n}\right) \rightarrow(x, y)$. we have

$$
x_{n+1}=F\left(x_{n}, y_{n}\right) \rightarrow F(x, y) .
$$

By the uniqueness of limit, we get that $x=F(x, y)$. Similarly, we show that $y=F(y, x)$.

So, $(x, y)$ is a coupled fixed point of $F$.

By taking $\varphi(t)=k t$, where $k \in(0,1]$, in Theorem 3.1, we have the following.

Corollary 3.2. Let $(X, \leq)$ be a partially ordered set and $(X, G)$ a complete $G$-metric space. Let $F: X \times X \rightarrow X$ be a continuous mapping such that $F$ has the mixed monotone property. Assume that there exists $k \in[0,1)$ such that

$$
\begin{aligned}
& (F(x, y), F(u, v), F(u, v)) \\
& \quad \leq k(\max (G(x, u, u), G(y, v, v))
\end{aligned}
$$

for all $x, y, u, v \in X$ with $x \geq u$ and $y \leq v$. If there exist $x_{0}, y_{0} \in X$ such that $x_{0} \leq F\left(x_{0}, y_{0}\right)$ and $y_{0}=F\left(y_{0}, x_{0}\right)$, then $F$ has a coupled fixed point.

As a consequence of Corollary 3.2, we have the following.

COROllary 3.3. Let $(X, \leq)$ be a partially ordered set and $(X, G)$ a complete $G$-metric space. Let $F: X \times X \rightarrow X$ be a continuous mapping such that $F$ has the mixed monotone property. Assume that there exists $a_{1}, a_{2} \in[0,1)$ such that

$$
\begin{aligned}
& (F(x, y), F(u, v), F(u, v)) \\
& \quad \leq a_{1}\left(G(x, u, u)+a_{2} G(y, v, v)\right)
\end{aligned}
$$


for all $x, y, u, v \in X$ with $x \geq u$ and $y \geq v$. If there exist $x_{0}, y_{0} \in X$ such that $x_{0} \leq F\left(x_{0}, y_{0}\right)$ and $y_{0} \geq F\left(y_{0}, x_{0}\right)$, then $F$ has a coupled fixed point.

THEOREM 3.4. Let $(X, \leq)$ be a partially ordered set and $(X, G)$ a complete $G$-metric space. Let $F: X \times X \rightarrow X$ be a mapping having mixed monotone property. Assume that there exists $\varphi \in \Phi$ such that

$$
\begin{aligned}
& G(F(x, y), F(u, v), F(u, v)) \\
& \quad \leq \varphi[\max (G(x, u, u), G(y, v, v))]
\end{aligned}
$$

for all $x, y, u, v \in X$ with $x \geq u$ and $y \leq v$.

Assume also that $X$ has the following properties:

(i) if a nondecreasing sequence $x_{n} \rightarrow x$, then $x_{n} \leq x$ for all $n \in N$,

(ii) if a nonincreasing sequence $y_{n} \rightarrow y$, then $y_{n} \geq y$ for all $n \in N$.

If there exist $x_{0}, y_{0} \in X$ such that $x_{0} \leq F\left(x_{0}, y_{0}\right)$ and $y_{0} \geq$ $F\left(y_{0}, x_{0}\right)$, then $F$ has a coupled fixed point.

Proof. By following the same process in Theorem 3.1, we construct two Cauchy sequences $x_{n}$ and $y_{n}$ in $X$ with

$$
x_{1} \leq x_{2} \leq \cdots \leq x_{n} \leq \cdots \text { and } y_{1} \geq y_{2} \geq \cdots \geq y_{n} \geq \cdots
$$

such that $x_{n} \rightarrow x \in X$ and $y_{n} \rightarrow y \in X$. By the hypotheses on $X$, we have $x_{n} \leq x$ and $y_{n} \geq y$ for all $n \in N$. From (16), we have

$$
\begin{aligned}
& G\left(F(x, y), x_{n+1}, x_{n+1}\right) \\
& \quad=G\left(F(x, y), F\left(x_{n}, y_{n}\right), F\left(x_{n}, y_{n}\right)\right) \\
& \quad \leq \varphi\left(\max \left(G\left(x, x_{n}, x_{n}\right), G\left(y, y_{n}, y_{n}\right)\right)\right. \\
& G\left(y_{n+1}, F(y, x), F(y, x)\right) \\
& \quad=G\left(F\left(y_{n}, x_{n}\right), F(y, x), F(y, x)\right) \\
& \quad=\varphi\left(\max \left(G\left(y_{n}, y, y\right), G\left(x_{n}, x, x\right)\right)\right.
\end{aligned}
$$

From (18) we get,

$$
\begin{gathered}
\max \left[G\left(F(x, y), x_{n+1}, x_{n+1}\right), G\left(y_{n+1}, F(y, x), F(y, x)\right)\right] \\
\leq \varphi\left(\max \left[G\left(x, x_{n}, x_{n}\right), G\left(y, y_{n}, y_{n}\right)\right),\right. \\
\left.\left.G\left(y_{n}, y, y\right), G\left(x_{n}, x, x\right)\right)\right] .
\end{gathered}
$$

Letting $n \rightarrow+\infty$ in (19), it follows that $x=F(x, y)$ and $y=F(y, x)$. Hence $(x, y)$ is a coupled fixed point of $F$.

By taking $\varphi(t)=k t$, where $k \in(0,1]$, in Theorem 3.4, we have the following result.

COROLlary 3.5. Let $(X, \leq)$ be a partially ordered set and $(X, G)$ a complete $G$-metric space. Let $F: X \times X \rightarrow X$ be a mapping having mixed monotone property. Assume that there exists $k \in[0,1)$ such that

$$
\begin{aligned}
& G(F(x, y), F(u, v), F(u, v)) \\
& \quad \leq k \max (G(x, u, u), G(y, v, v))
\end{aligned}
$$

for all $x, y, u, v \in X$ with $x \geq u$ and $y \leq v$.

Assume also that $X$ has the following properties:

(i) if a nondecreasing sequence $x_{n} \rightarrow x$, then $x_{n} \leq x$ for all $n \in N$, (ii) if a nonincreasing sequence $y_{n} \rightarrow y$, then $y_{n} \geq y$ for all $n \in N$.

If there exist $x_{0}, y_{0} \in X$ such that $x_{0} \leq F\left(x_{0}, y_{0}\right)$ and $y_{0} \geq$ $F\left(y_{0}, x_{0}\right)$, then $F$ has a coupled fixed point.

As a consequence of Corollary 3.5, we have the following.

COROLlary 3.6. Let $(X, \leq)$ be a partially ordered set and $(X, G)$ a complete $G$-metric space. Let $F: X \times X \rightarrow X$ be a mapping having mixed monotone property. Assume that there exists $a_{1}, a_{2} \in[0,1)$ such that

$$
\begin{aligned}
& G(F(x, y), F(u, v), F(u, v)) \\
& \quad \leq a_{1}\left(G(x, u, u)+a_{2} G(y, v, v)\right)
\end{aligned}
$$

for all $x, y, u, v \in X$ with $x \geq u$ and $y \leq v$.

Assume also that $X$ has the following properties:

(i) if a nondecreasing sequence $x_{n} \rightarrow x$, then $x_{n} \leq x$ for all $n \in N$,

(ii) if a nonincreasing sequence $y_{n} \rightarrow y$, then $y_{n} \geq y$ for all $n \in N$.

If there exist $x_{0}, y_{0} \in X$ such that $x_{0} \leq F\left(x_{0}, y_{0}\right)$ and $y_{0} \geq$ $F\left(y_{0}, x_{0}\right)$, then $F$ has a coupled fixed point.

\section{REFERENCES}

[1] T.G. Bhaskar and V. Lakshmikantham. Fixed point theory in partially ordered metric spaces and applications. Nonlinear Anal., 65.

[2] D.W. Boyd and S.W. Wong. On nonlinear contractions. Proc. Am. Math. Soc., 20.

[3] W. Shatanawi Erdal Karapinar and Z. Mustafa. Quadruple fixed point theorems under nonlinear contractive conditions in partially ordered metric spaces. Journal of Applied Mathematics.

[4] Z. Mustafa. A new structure for generalized metric spaces with applications to fixed point theory.

[5] Z. Mustafa and B. Sims. Fixed point theorems for contractive mappings in complete G-metric spaces. Fixed Point Theory Appl., 10.

[6] Z. Mustafa and B. Sims. A new approach to generalized metric spaces. J. Nonlinear Convex Anal., 7(2):289-297, 2006.

[7] H. Obiedat Z. Mustafa and F. Awawdeh. Some fixed point theorem for mapping on complete metric spaces. Fixed Point Theory Appl., 12. 